\title{
GESTORES DE JALECO
}

\section{A gestão hospitalar e de serviços de saúde no Brasil passa por um processo de profissionalização. Apesar dos avanços recentes, ainda há bastante escassez de gestores com formação adequada. Muitos profissionais buscam cursos de especialização na área}

\footnotetext{
Os problemas enfrentados na gestão hospitalar e de serviços de saúde no Brasil são amplamente conhecidos. No sistema público, as dificuldades são visíveis nas filas para atendimento e na escassez de leitos, médicos e infraestrutura. No sistema privado, apenas para citar um exemplo, as operadoras de planos de saúde lideram há mais de 10 anos os rankings de reclamações aos órgãos de defesa do consumidor. E o quadro fica ainda mais complexo quando consideramos as dimensões e o peso econômico do setor. Em seu conjunto, o setor produtivo da saúde emprega 10 milhões de profissionais e movimenta anualmente 160 bilhões de reais, respondendo por mais de 8\% do PIB.

Mas há um lado dessa história que é um pouco menos conhecido. Nele estão, por exemplo, o médico Nacime Salomão Mansur e a enfermeira de formação Aglaé Neri Gambirasio, entre inúmeros outros profissionais responsáveis pela gestão de estabelecimentos de saúde, e sobre os quais recai a difícil tarefa de manter o atendimento no melhor padrão possível, dentro das limitações, e melhorar os serviços prestados.
} 


$$
88
$$


EU ERA MÉDICO E VIREI GESTOR. Esses profissionais costumam ter uma característica em comum na biografia: embora com formação original na área da saúde, em algum momento tiveram que acrescentar à indumentária branca responsabilidades gerenciais. Via de regra, encontraram, na vida prática, dificuldades para as quais nunca tinham se preparado formalmente. "A primeira dificuldade foi perceber que administrar um hospital significa muito mais do que eu fazia como médico. Não é mais simplesmente reunir o doutor e o doente frente a frente: é preciso entender o que representam uma farmácia ou uma cozinha hospitalar, por exemplo, entre outras partes de um complexo conjunto de elementos, fluxos e processos imprescindíveis ao funcionamento de um hospital, que precisa ser administrado", explica Mansur.

\section{A gestão hospitalar no Brasil está se modernizando, mas carece de profissionais com formação adequada}

Formado pela Escola Paulista de Medicina em 1981, com residência médica e mestrado na mesma instituição, Mansur passou a atuar como gestor a partir de 1998. Antes disso, já havia exercido alguns cargos de chefia de equipes médicas, mas não tinha se envolvido diretamente com administração. "Em 1998, o governo de São Paulo procurou alguns parceiros para assumir a gestão de 14 hospitais públicos. A Unifesp foi convidada para assumir o de Pirajuçara, e eu, que na época era cirurgião gástrico, fui chamado para montar o hospital", explica. "Eu nunca tinha entrado em uma cozinha hospitalar, não entendia uma farmácia hospitalar, não conhecia as áreas de apoio, e tinha que montar um hospital de 280 leitos, cravado em uma região paupérrima e com carências de atendimento evidentes". Nesse cenário, o caminho encontrado por Mansur foi buscar formação específica em gestão.

Começou cursando o CEAHS, Curso de Especialização em Administração Hospitalar e Sistemas de Saúde da FGVEAESP. Em seguida, cursou também um MBA em gestão empresarial. "Eu precisava me capacitar, preencher uma lacuna de conhecimento em gestão. O CEAHS me deu algumas ferramentas e abriu perspectivas. Hoje estamos com 10 hospitais, e o de Pirajuçara, onde começamos, possui acreditação de qualidade internacional. É um dos únicos hospitais públicos do Brasil com esse tipo de acreditação", orgulha-se Mansur.

FORMAÇÕES COMPLEMENTARES. Trajetória parecida teve a enfermeira, e atual assistente técnica da Coordenadoria do Controle de Doenças da Secretaria Estadual de Saúde de São Paulo, Aglaé Neri Gambirasio. Ela se graduou em enfermagem pela PUC-Campinas, especializando-se em seguida em enfermagem médico-cirúrgica na Unifesp. Na década de 1980, foi professora-assistente e também supervisora de estágios em clínica médica na PUC-Campinas, tomando contato pela primeira vez com atividades de gestão. "Ao me desligar da instituição e ingressar no serviço público, passei a gerenciar uma unidade básica de saúde e participar das atividades de treinamento de pessoal. A partir daí, fui assumindo a seleção de pessoal, depois a administração de RH, e assim por diante", explica.

Com o tempo, Aglaé passou a atuar exclusivamente como gestora, e isso a levou a procurar o CEAHS da FGVEAESP a fim de especializar-se. O que não significa que a formação original em enfermagem deixou de ter importância nesta nova fase. "A enfermeira nunca deixou de existir na minha atuação, e algumas vezes sinto falta da atividade de cuidar, especialmente agora, que estou na sede da Secretaria de Saúde", explica. Mansur concorda: "O profissional sem formação em saúde pode ser um excelente gestor nesta área. Mas nós temos uma particularidade especial, 
porque conhecemos melhor o ambiente. Eu não sou aquele gestor que chega e diz: 'Preciso reduzir custo, então vou cortar $20 \%$ e não quero saber'. Nós conseguimos ter um olhar diferente, mais subjetivo, uma atenção com o lado humano. Quem militou na profissão sabe como é".

\section{Ao assumirem cargos de gestão, médicos e demais profissionais de saúde encontram desafios para os quais não foram formalmente educados}

DIAGNÓSTICO DO SETOR. No Brasil existem cerca de 7 mil hospitais, 3 mil operadoras de saúde (convênios médicos), além das agências reguladoras de saúde, secretarias de saúde estaduais e municipais etc. A realidade do setor ainda é distante do ideal para o país, mas mesmo assim tem havido inegáveis progressos. O aumento no número de instituições, a crescente complexidade dos processos de trabalho e os avanços tecnológicos têm modificado a forma de se pensar a administração hospitalar, e isso exige cada vez mais profissionalização.

Ana Maria Malik, professora da FVG-EAESP e coordenadora do Centro de Estudos em Planejamento e Gestão da Saúde (GVsaúde), explica que esse mercado requer um conhecimento que antes não era percebido como necessário. "O setor é caracterizado pela quantidade elevada de empresas familiares, e o número de profissionais pouco preparados para um cargo de gestão é alto. Felizmente, hoje nos grandes hospitais o CEO já costuma ser um médico com formação em gestão. Mas nas instituições menores isso nem sempre é a regra, ainda", explica.

A professora menciona as áreas de Marketing, Finanças e Recursos Humanos como as que apresentam maiores deficiências. "Os profissionais que estão no comando de hospitais não têm noção da importância da área de Marketing. Eles imaginam que se refere apenas a propaganda, quando isso na verdade é uma parte pequena do que ensinamos aqui na FGV-EAESP. Custos e Finanças também são fundamentais para qualquer empresa, mas no setor de saúde ainda costumam ser administrados amadoristicamente", explica.

ÚLTIMA FRONTEIRA. "Eu costumo dizer, brincando, que o setor hospitalar é a última fronteira da Administração", diz Mansur. "É preciso profissionalizar a gestão do setor e acabar com a falta de controle, as incertezas e o achismo que há dentro do sistema", explica.

Essa aposta já se reflete na demanda por capacitação. "Dentro dos cursos de especialização houve, nos últimos anos, um rejuvenescimento das turmas. No início eram profissionais experientes, que já exerciam cargos de gestão e queriam solidificar ou formalizar o conhecimento. E eram, na sua maioria, médicos. Com o passar dos anos, profissionais de outras áreas da saúde e de outras formações, como comunicação e exatas, passaram a procurar nossos cursos", relembra Ana Maria Malik.

\section{Marketing, Finanças e Recursos Humanos são as áreas com maior carência de profissionalização nas empresas do setor}

"O sistema, apesar de tudo, ainda é bastante amador. Precisa ter mais gestão, mais conhecimento, mais informação e mais profissionalização", finaliza Mansur.

RAFAEL VALENTE, jornalista, jornalismo.rafael@gmail.com 